\title{
Uterine Epithelial Changes During Placentation in the Viviparous Skink Eulamprus tympanum
}

\author{
Susan M. Adams, ${ }^{1,2 \star}$ Sylvia Lui, ${ }^{2}$ Susan M. Jones, ${ }^{3}$ Michael B. Thompson, ${ }^{1}$ \\ and Christopher R. Murphy ${ }^{2}$ \\ ${ }^{1}$ School of Biological Sciences and Wildlife Research Institute, The University of Sydney, \\ New South Wales 2006, Australia \\ ${ }^{2}$ School of Medical Sciences (Anatomy and Histology), The University of Sydney, New South Wales 2006, Australia \\ ${ }^{3}$ Comparative Endocrinological Research Group, School of Zoology, University of Tasmania, Hobart, \\ Tasmania 7001, Australia
}

ABSTRACT We used scanning electron microscopy (SEM) and transmission electron microscopy (TEM) to describe the complete ontogeny of simple placentation and the development of both the yolk sac placentae and chorioallantoic placentae from nonreproductive through postparturition phases in the maternal uterine epithelium of the Australian skink, Eulamprus tympanum. We chose $E$. tympanum, a species with a simple, noninvasive placenta, and which we know, has little net nutrient uptake during gestation to develop hypotheses about placental function and to identify any difference between the oviparous and viviparous conditions. Placental differentiation into the chorioallantoic placenta and yolk sac placenta occurs from embryonic Stage 29; both placentae are simple structures without specialized features for materno/fetal connection. The uterine epithelial cells are not squamous as previously described by Claire Weekes, but are columnar, becoming increasingly attenuated because of the pressure of the impinging underlying capillaries as gestation progresses. When the females are nonreproductive, the luminal uterine surface is flat and the microvillous cells that contain electrondense vesicles partly obscure the ciliated cells. As vitellogenesis progresses, the microvillous cells are less hypertrophied than in nonreproductive females. After ovulation and fertilization, there is no regional differentiation of the uterine epithelium around the circumference of the egg. The first differentiation, associated with the chorioallantoic placentae and yolk sac placentae, occurs at embryonic Stage 29 and continues through to Stage 39. As gestation proceeds, the uterine chorioallantoic placenta forms ridges, the microvillous cells become less hypertrophied, ciliated cells are less abundant, the underlying blood vessels increase in size, and the gland openings at the uterine surface are more apparent. In contrast, the yolk sac placenta has no particular folding with cells having a random orientation and where the microvillous cells remain hypertrophied throughout gestation. However, the ciliated cells become less abundant as gestation proceeds, as also seen in the chorioallantoic placenta. Secretory vesicles are visible in the uterine lumen. All placental differentiation and cell detail is lost at Stage 40 , and the uterine structure has returned to the nonreproductive condition within 2 weeks. Circulating progesterone concentrations begin to rise during late vitellogenesis, peak at embryonic Stages 28-30, and decline after Stage 35 in the later stages of gestation. The coincidence between the time of oviposition and placental differentiation demonstrates a similarity during gestation in the uterus between oviparous and simple placental viviparous squamates. J. Morphol. 268:385-400, 2007. @ 2007 Wiley-Liss, Inc.

KEY WORDS: uterine epithelium; scanning electron microscopy; skink; plasma membrane transformation; placental morphology

Viviparity has numerous independent origins in vertebrates. Most of these lineages originate more frequently in reptilian evolution than in any other vertebrate (Blackburn, 1993; Smith and Shine, 1997). Viviparity in the extant reptile fauna occurs only in the Squamata (lizards and snakes), which also has oviparous species (Smith and Shine, 1997).

Most of the nutrients required by the developing embryo in oviparous species are encased within the egg shell, whereas viviparity provides added opportunity for the provision of nutrients to the egg and embryo. Several fundamental changes have occurred to accommodate the increase in egg retention and longer in utero incubation in the switch in reproductive mode from oviparity to viviparity (Shine and Bull, 1979). During the evolution of viviparity, maternal tissues needed to respond to a greater need for oxygen and water exchange than in oviparous species. Calcium, normally supplemented by the eggshell in oviparous species, also had to be supplemented by the mother, presumably resulting in modification to uterine function and development (Packard et al., 1977; Andrews, 2004).

\footnotetext{
Contract grant sponsor: ARC Discovery.

*Correspondence to: Dr. Susan Adams, School of Medical Sciences (Anatomy and Histology), Anderson Stuart Building F13, The University of Sydney, New South Wales 2006, Australia.

E-mail: susan@anatomy.usyd.edu.au
}

Published online 13 March 2007 in

Wiley InterScience (www.interscience.wiley.com)

DOI: $10.1002 /$ jmor. 10520 
Placental development in lizards involves both maternal and fetal tissues forming a noninvasive placenta but does not involve the invasiveness and complex breakdown and reconstruction of maternal uterine tissue of some eutherian mammals (Blackburn, 1993; Murphy et al., 2000). The evolutionary framework of four placental types in squamate reptiles based on the chorioallantoic placenta (Weekes, 1935; Blackburn, 1993) is proving to be somewhat of a simplification now that more descriptions of placentae, and how they change during gestation, become available (Stewart and Thompson, 2000). The original categories do not include the yolk sac placental structure and do not account for cellular changes during the development of gestation. Electron microscopy can now accurately show cellular details that were not suspected previously.

We used scanning electron microscopy (SEM) and transmission electron microscopy (TEM) to correlate the surface topography to the underlying ultrastructure and reveal correlations between placental structure and potential function. The morphological features of the uterine epithelium from a quiescent state, through gestation to postparturition, and changes in plasma progesterone during gestation, are described for a complete ontogeny of the reptilian chorioallantoic Type I simple placenta, adding further to the Weekes (1935) Type-I classification and contributing to understanding possible morphological functions in a Type I "simple" placenta.

\section{MATERIALS AND METHODS Animal Collection}

Fifty Eulamprus tympanum (Repilia, Squamata, Scincidae) females (snout vent length: 72-86 mm; weight: 7.4-15 g) were collected from Kanangra Boyd National Park, New South Wales, Australia, (33 $\left.{ }^{\circ} 59^{\prime} \mathrm{S}, 150^{\circ} 03^{\prime} \mathrm{E}\right)$ between November 2003 and January 2004 by hand using a lure (Durden et al., 1995). Lizards were sexed in the field and the females transported to the University of Sydney. They were housed in individual glass aquaria $(420 \mathrm{~mm} \times 240 \mathrm{~mm} \times 200 \mathrm{~mm})$ in a temperature-controlled room $\left(19-21^{\circ} \mathrm{C}\right)$. Heat was provided for $9 \mathrm{~h} /$ day by a $25-$ $\mathrm{W}$ incandescent heat lamp suspended over one end of the aquarium, creating a thermal gradient of $20-35^{\circ} \mathrm{C}$ so that the animals could thermoregulate at will. Water was provided $a d$ libitum and mealworms (Tenebrio molitor) and crickets (Acheta domestica) dusted with Herptivite (multivitamins) and phosphorous-free calcium with Vitamin D supplement (Rep-Cal ${ }^{\mathbb{R}}$ Research Labs, CA) were offered every second day. Shelter was provided in the form of rocks, bark, and leaf litter.

\section{Tissue Preparation and Electron Microscopy}

Females were selected for dissection by gently palpating the abdomen with a forefinger and thumb for the size of the embryos. Skinks were euthanased by intrathoracic lethal injection of $0.1 \mathrm{ml}$ of sodium pentobarbitone (Nembutal, Merial). Their necks were cut, severing the central vertebrae and major blood vessels. Blood was collected in heparinized microhematoc- rit capillary tubes (Red Tip, Sherwood Medical Industries, USA) and transferred to $1.5 \mathrm{ml}$ ependorf tubes. Blood was stored on ice for at least an hour before being centrifuged. Plasma was placed into a fresh ependorf tube and frozen in liquid nitrogen prior to radioimmunoassay. A ventral incision exposed the oviducts and the uteri were removed, with intact embryos if pregnant. The number, appearance, and size of the ovarian follicles were recorded. Dissection and fixation of uteri were carried out in 2.5\% EM grade glutaraldehyde (AGAR Scientific, UK) in 0.1 M phosphate buffer, pH7.4 (PB). The uteri were sectioned transversely into the respective uterine egg chambers, which were then cut longitudinally to expose the uterine lumen. The embryos were removed and fixed in $10 \%$ neutral buffered formalin for later embryo staging using the scheme of Dufaure and Hubert (1961). The sections were fixed in $2.5 \%$ glutaraldehyde for $1 \mathrm{~h}$ and then randomly allocated for TEM and SEM. The tissues were rinsed in phosphate buffer, postfixed for $1 \mathrm{~h}$ in aqueous $1 \%$ osmium tetroxide $\left(\mathrm{OsO}_{4}\right)$ (Johnson Matthey Chemicals, Royston, Hertfordshire, UK) and dehydrated through graded ethanols $50-100 \%$. The groups obtained for analysis were nonreproductive, vitellogenic, the stages early through to late gestation (Table 1), and $48 \mathrm{~h}$ and 2 weeks postpartum.

Tissues were critical point dried (Bal-Tec CPD 030) for SEM. Dried tissue was mounted onto aluminum stubs, sputter coated to $20 \mathrm{~nm}$ with gold, viewed using a Philips Scanning Electron Microscope 505 (The Netherlands) operating at $20 \mathrm{kV}$, and with ImageSlave Screen Capture Utility software (Melbourne, Australia).

For TEM, the tissue was infiltrated with $50 \%$ Spurr resin/acetone for $2 \mathrm{~h}$ and transferred to fresh Spurr 100\% resin (Agar Scientific, Essex, UK) overnight, embedded in Spurr resin in flat cassette molds (ProSci Tech, Queensland, Australia), and polymerized at $60^{\circ} \mathrm{C}$ for $24 \mathrm{~h}$. Semithin sections $0.5 \mu \mathrm{m}$ were cut and stained with toludine blue to determine the presence of epithelium prior to further trimming. Ribbons of ultrathin (70 $\mathrm{nm}$ ) sections were cut on an Ultracut E1 ultramicrotome (Leica, Germany), and placed onto 200-mesh copper grids (Agar Scientific, Essex, UK). Sections were counterstained in $4 \%$ aqueous uranyl acetate for $45 \mathrm{~min}$, and Reynolds lead citrate for $8 \mathrm{~min}$. Five grids per specimen were examined using a Zeiss 902 (Germany) electron microscope operating at $80 \mathrm{kV}$ and images were digitally captured with a Gatan BioScan digital camera (CA) and Digital Micrograph 3.3 computer software.

TABLE 1. Stages of placental development and sample size obtained for SEM and TEM following the embryonic staging of Dufaure and Hubert (1961)

\begin{tabular}{lccc}
\hline SEM & TEM & Animals per stage & Gestation \\
\hline NR & NR & 6 & Non \\
VIT & VIT & 5 & \\
EG & EG & 5 & Early \\
- & 26 & 1 & \\
28 & 28 & 1 & Mid \\
29 & - & 2 & \\
30 & - & 1 & \\
31 & 31 & 3 & \\
32 & 32 & 3 & \\
- & 33 & 1 & \\
34 & - & 1 & \\
35 & 35 & 4 & \\
36 & 36 & 5 & \\
37 & - & 1 & \\
38 & - & 1 & \\
39 & 39 & 2 & \\
40 & 40 & 2 & \\
48 h POST & 48 h POST & 3 & \\
2 wk POST & 2 wk POST & 3 & \\
\hline
\end{tabular}

NR, nonreproductive; VIT, vitellogenic; EG, early gestation; POST, postparturition. 

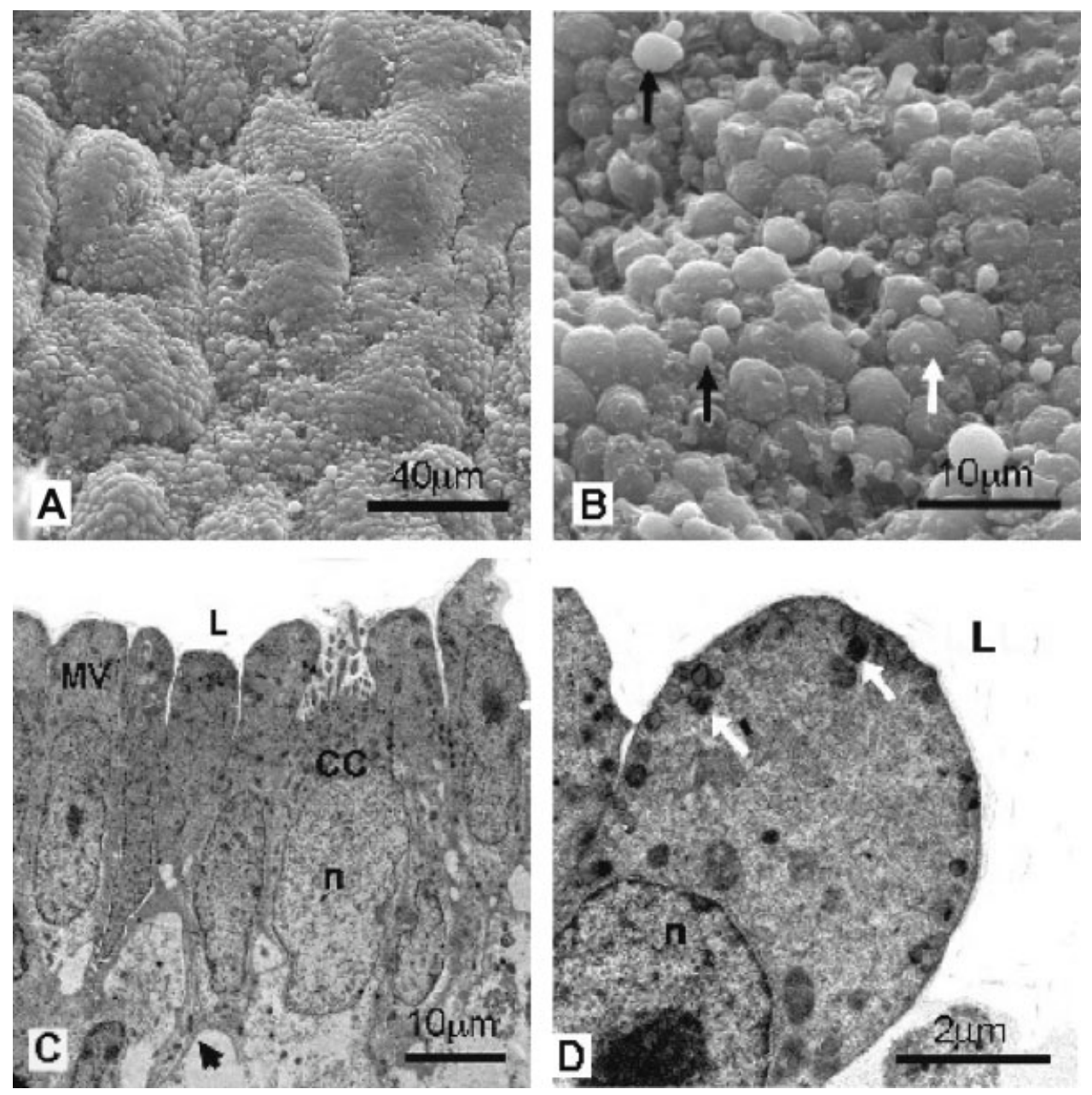

Fig. 1. Nonreproductive uterine epithelium of Eulamprus tympanum. A: At low magnification, the uterine epithelial surface is relatively flat; SEM. B: Higher magnification of the same cells showing the knobbled surface of the microvillous cells (white arrow) and secretory vesicles (black arrows); SEM. C: Ciliated cell (CC) with apical cilia obscured by adjacent hypertrophied microvillous cells (MV); TEM. D: Higher magnification of a microvillous cell with electron-dense vesicles in the cytoplasm (white arrows); TEM. n, nucleus; L, uterine lumen; arrowhead, basal lamina.

\section{Radioimmunoassay of Progesterone}

Plasma samples of $15-25 \mu \mathrm{l}$ were extracted in 1-ml iso-octane with a mean efficiency of $93 \%$. Extracts were assayed by radioimmunoassay using a technique previously validated for lizard plasma (Jones and Swain, 1996); results were corrected for extraction efficiency and plasma volume. The antiserum was Sirosera ${ }^{\mathrm{TM}}$ C-9817 progesterone antiserum used at a dilution of 1:250,000 in phosgel (phosphate buffer $\mathrm{pH} 7.6$ with $1 \%$ gelatin). All samples were assayed in a single assay, assay accuracy was checked by inclusion of human multivalent control sera (CON6: Diagnostic Products), and the limit of detection was $0.18 \mathrm{ng} / \mathrm{ml}$ plasma (for $25 \mu \mathrm{l}$ samples).

\section{RESULTS}

In mammals, uterine epithelial cells are described as microvillous and ciliated (Martel et al., 1981; Psychoyos and Nikas, 1994). In more general biological literature, the two cell types, on the other hand, are referred to as ciliated and nonciliated. For the sake of consistency (Junqueira and
Carneiro, 2005), and because a plasma membrane transformation has been shown to occur with varying degrees of microvillous rearrangement, we describe these major cell types in reptiles as ciliated or microvillous cells.

\section{Nonreproductive}

We use the term "nonreproductive" to refer to an adult female where embryos are absent from the uterus, but the uteri have a characteristic flaccid appearance suggestive of reproduction in a previous season, and the ovaries are without vitellogenic follicles $(<2 \mathrm{~mm})$. The uterine luminal surface is flattened and without distinctive folding (Fig. 1A). The microvillous cells are columnar and protrude maximally into the lumen (Fig. 1B), such that the ciliated cells are either obscured completely by this protrusion (Fig. 1C), or cause the cilia to appear short and numerically reduced 

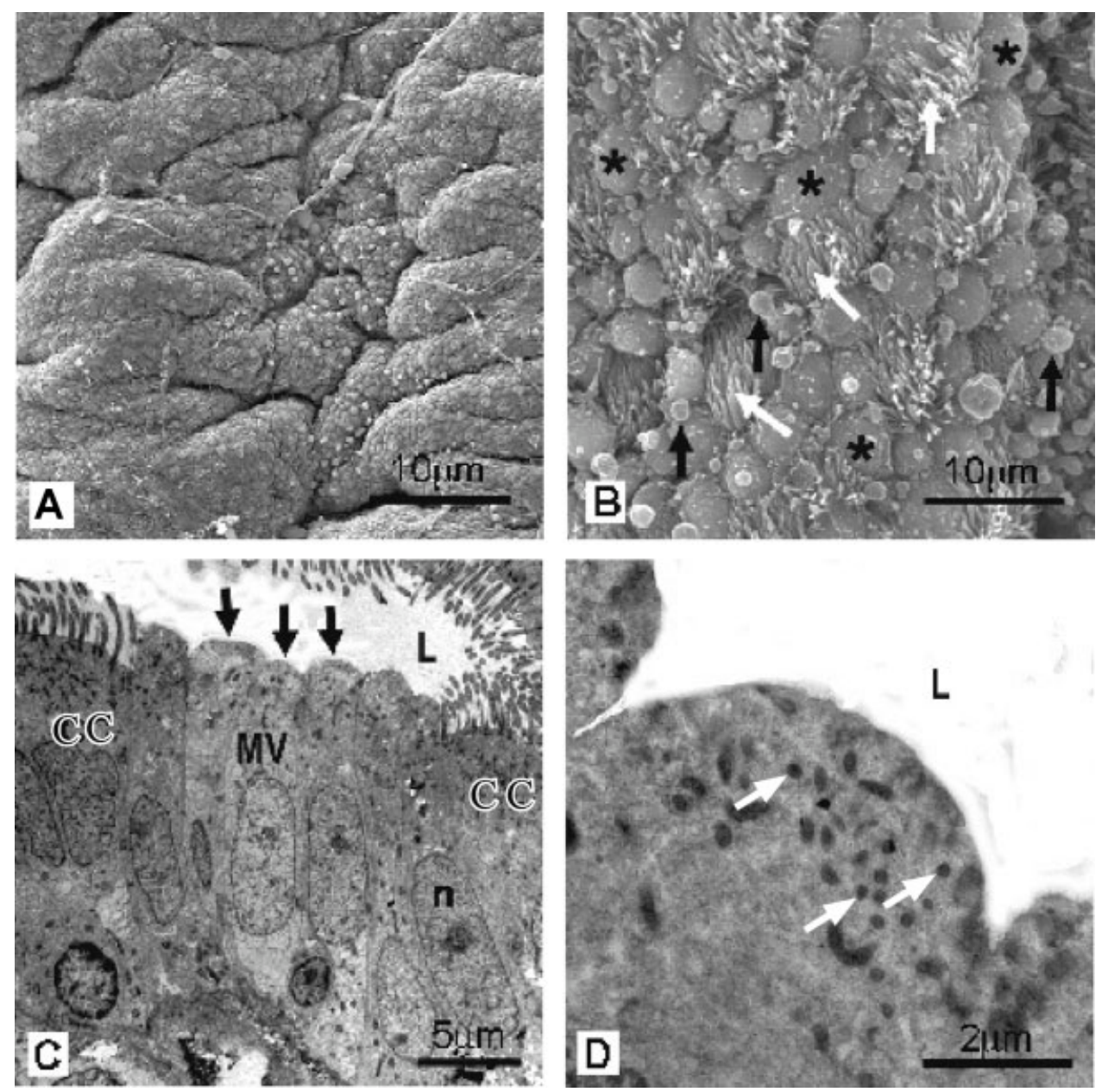

Fig. 2. Vitellogenic uterine epithelium of Eulamprus tympanum. A: The surface topography shows deepening folds and both uterine epithelial cell types, ciliated cells, and microvillous cells; SEM. B: Higher magnification of A shows the ciliated cells (white arrows), microvillous cells with knobbled surfaces (asterix), and secretory droplets (black arrows); SEM. C: Columnar microvillous cells (MV) with reduced hypertrophied apices (black arrows) and greater abundance of ciliated cells (CC); TEM. D: Higher magnification of $\mathrm{C}$ shows the smooth apical surface of a microvillous cell and a greater abundance of electron-dense vesicles (white arrows) when compared to nonreproductive epithelium. n, nucleus; L, uterine lumen.

(Fig. 1B). The plasma membrane of the microvillous cells is smooth and bare of microvilli (Fig. 1D); however, the apical cell membrane often has a knobbled appearance (Fig. 1B). Small, electron-dense vesicles occur throughout the cells, with slight aggregation in the apical region (Fig. 1D). There is an abundance of secretory vesicles (Fig. 1B).

\section{Vitellogenic}

"Vitellogenic" refers to females with yellow yolky follicles $(>2 \mathrm{~mm})$ in the ovaries just prior to ovulation. The uterine epithelium has deepening folds (Fig. 2A) and consists of microvillous cells and a greater abundance of mature ciliated cells (Fig. 2B). The microvillous cells are columnar with a knobbled apical surface, but the apical hypertrophy is not as great as in nonreproductive females. This reduced cell height allows the ciliated cells to be seen (Fig. 2B,C). It is probable that the ciliated cells are also more numerous, as well as more exposed by the reduced height of the microvillous cells. There is a similar scattering of small electron-dense vesicles throughout each cell (Fig. 2D) compared to those in nonreproductive females, but with a greater localization in the apical cytoplasm.

\section{Early Gestation}

Early gestation refers to postovulatory females with embryos up to Stage 28 (Dufaure and Hubert, 1961), as there are no discernable differences in the epithelial response to suggest placental differentiation through this whole period. The luminal uterine morphology is different from that of nonpregnant uteri during early gestation. The uterine epithelium has distinctive folds (Fig. 3A). The two cell types (ciliated and microvillous) are present and evenly dispersed across the folds (Fig. 3A,B). 

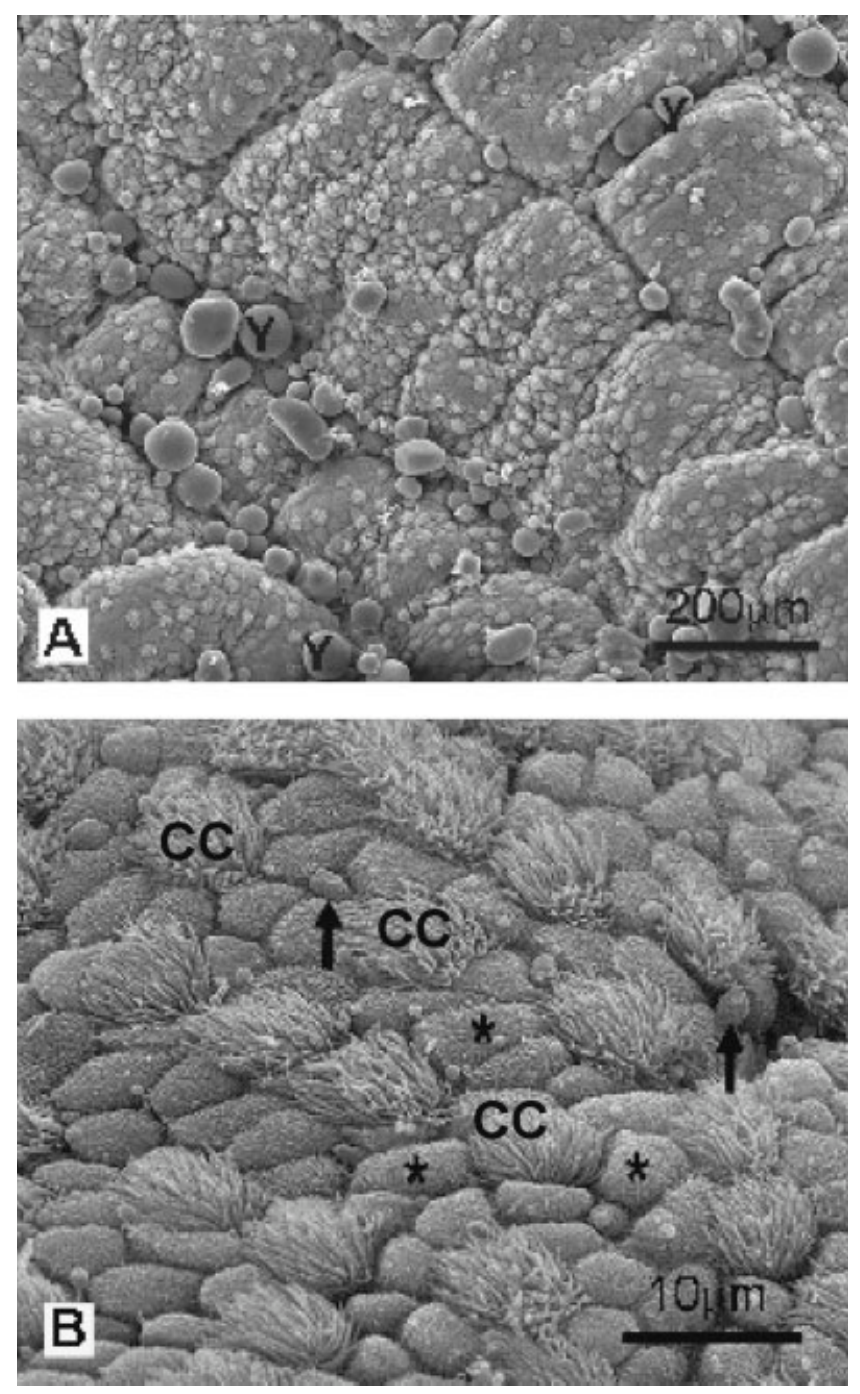

Fig. 3. Early gestation uterine epithelium of Eulamprus tympanum. A: Distinctive radial folding with a uniform distribution of ciliated and microvillous cells; SEM. B: Higher magnification of the same area shows reduced number of small secretory droplets (arrows), dense, plicate microvilli covering of the microvillous cells (asterix) and evenly distributed ciliated cells (CC); SEM. Y, yolk droplets.

The microvilli on the microvillous cells are dense and plicate (Fig. 3B). In comparison with the nonreproductive stage, the cell apices are further reduced and there are fewer secretory droplets present on the surface (Fig. 3B). At this stage of gestation, there is no obvious differentiation of the chorioallantoic placentae and yolk sac placentae in the uterus. Electron-dense vesicles still appear in the apical cytoplasm.

\section{Placental Differentiation}

Embryonic Stage 29 is the first stage that shows uterine epithelial differentiation into two distinct placentae: the chorioallantoic placenta and yolk sac placenta.

\section{Chorioallantoic placenta}

At Stage 29, there is a formalized epithelial ridge. The area surrounding this ridge is randomly folded (Fig. 4B), but the ridge develops into a series of radially oriented, parallel ridges by Stage 35 (Fig. 5A). The microvillous cells flatten down further than in earlier stages (Fig. 4A,C), and by Stage 35, the adjoining cell borders are apparent because of further loss of apical protrusion (Fig. 5C). The apical plasma membrane is transformed into dense, short microvilli (Figs. 4C and 5C). Several gland openings are visible on the luminal surface (Fig. 4D). Ciliated cells are further reduced or absent altogether during the later stages of mid-gestation. As gestation progresses through mid-gestation, the blood vessels underlying the epithelial cells cause a variability in cell size and shape (Fig. 5B), as the vessels variously impinge into the epithelial cell space causing clusters of epithelial cells to become stretched in the apical region of the cytoplasm (Fig. 5C). The smaller, microvillous cells at Stages 36 and 37 have a maximally protruding apex with bare plasma membranes in varying stages of development (Fig. 5E), whereas adjoining cells have minimal apical protrusion and are abundantly covered with low, microvilli (Fig. 5F). There is a reduction in secretory droplets. Large electron-dense vesicles are sparsely dispersed throughout the microvillous cells (Fig. 5D).

Only microvillous cells are evident in the uterine epithelium in late gestation. The formally folded epithelial ridges appear more densely arranged with microvillous cells of various size (Fig. 6A). The further increase in cell size and shape results in a convex epithelial pouching (Fig. 6A), as the underlying blood vessels continue to expand, causing patches of flattened, stretched cells, and obvious cell borders on the ridge crests, and smaller minimally protruding cells in the gulleys (Fig. 6A,B). Continued expansion of the underlying blood vessels causes the epithelial cell nuclei to be laterally displaced, which further reduces the luminal epithelial barrier (Fig. 6C,D). The stretched cells on the ridges have a flattened appearance and plicate microvilli (Fig. 6B,D). Ultrastructural observation confirms the cell size variability from columnar to stretched cuboidal. Electron-dense and electron-lucent vesicles are present in the epithelial cells at Stage 39 (Fig. 6D).

\section{Yolk sac placenta}

There is no particular folding pattern in the uterine epithelium of the yolk sac placenta. Both 

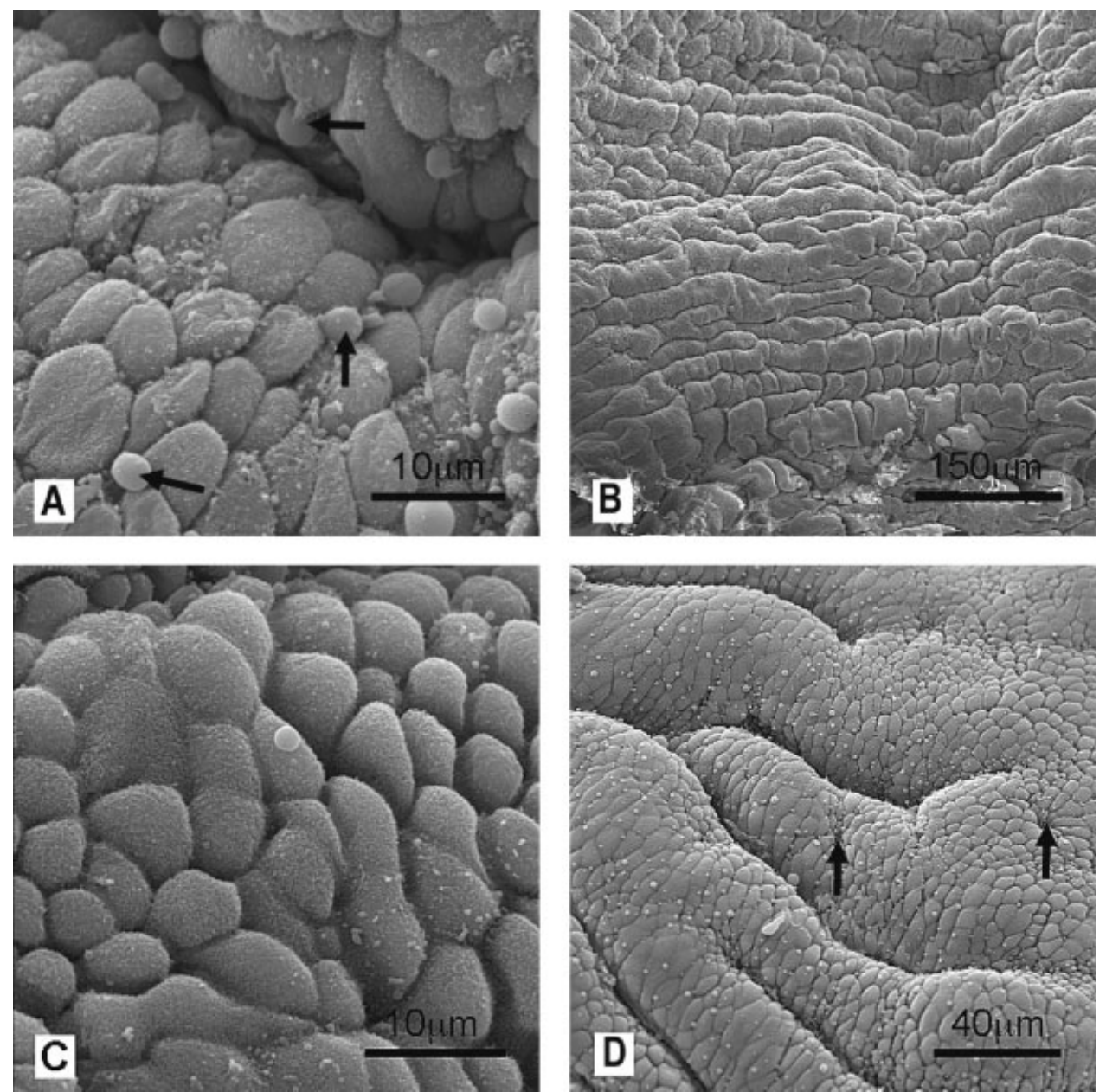

Fig. 4. Chorioallantoic placental differentiation; embryonic Stages 29-33 of Eulamprus tympanum; SEM. A: Stage 29 apical protrusion of the microvillous cells has flattened down. Secretory vesicles are seen (black arrows). B: Stages 31-32. The uterine topography is formally folded into a series of radially oriented, parallel ridges. C: Higher magnification of B shows dense, short microvilli on the luminal surface of the microvillous cells. D: Stages 32-33. Several gland openings on the luminal surface (black arrows).

ciliated and microvillous cells occur throughout the yolk sac placenta at Stage 29. The ciliated cells are smaller in size and reduced in ciliation compared to the nondifferentiated preceding stages (Fig. 7A). They are sunken and the cilia are numerically reduced or absent altogether. The microvillous cells protrude moderately into the lumen are columnar and covered with short, blebbed microvilli (Fig. 7A). Secretory droplets and vesicles are present. The uterine epithelium of the yolk sac placenta at Stages 31-32 is different from the chorioallantoic placenta as there are no areas of stretched, flattened cells, ridges, or patterns of distinct folding (Fig. 7B). Ciliated cells are no longer present and the microvillous cells are uniform in shape and size. The apical protrusion is reduced in comparison with that of Stage 29. The apical cytoplasm (TEM) has a thick band of electron-dense vesicles (Fig. 7C), with secretory droplets that correspond to those viewed in SEM.
By Stage 35, the epithelial arrangement is still random but has lost the flat appearance and is now raised or ruched (Fig. 8A). The apical plasma membrane has a "knobbled" appearance (Fig. 8B) and the blebbed microvilli of earlier stages are reduced, suggesting a plasma membrane transformation as the apical surface flattens down (Fig. 8C). Both the electron-dense vesicles and the secretory droplets are greatly reduced (Fig. 8C).

The embryonic stages from mid-gestation to Stage 39 are subtle. The epithelial folding remains random and bulging. The cells are microvillous and there is now a large variability in size and shape (Fig. 9A,C). Their apical protrusion is minimal and they have short microvilli on the apical periphery and where the cell borders become more apparent (Fig. 9A). The central apice retains its "knobbled" appearance, which becomes more pronounced as gestation progresses to Stage 39 (Fig. 9C). Wrinkled apical plasma membranes show cells in various stages of collapse at Stage 38 (Fig. 9B). 

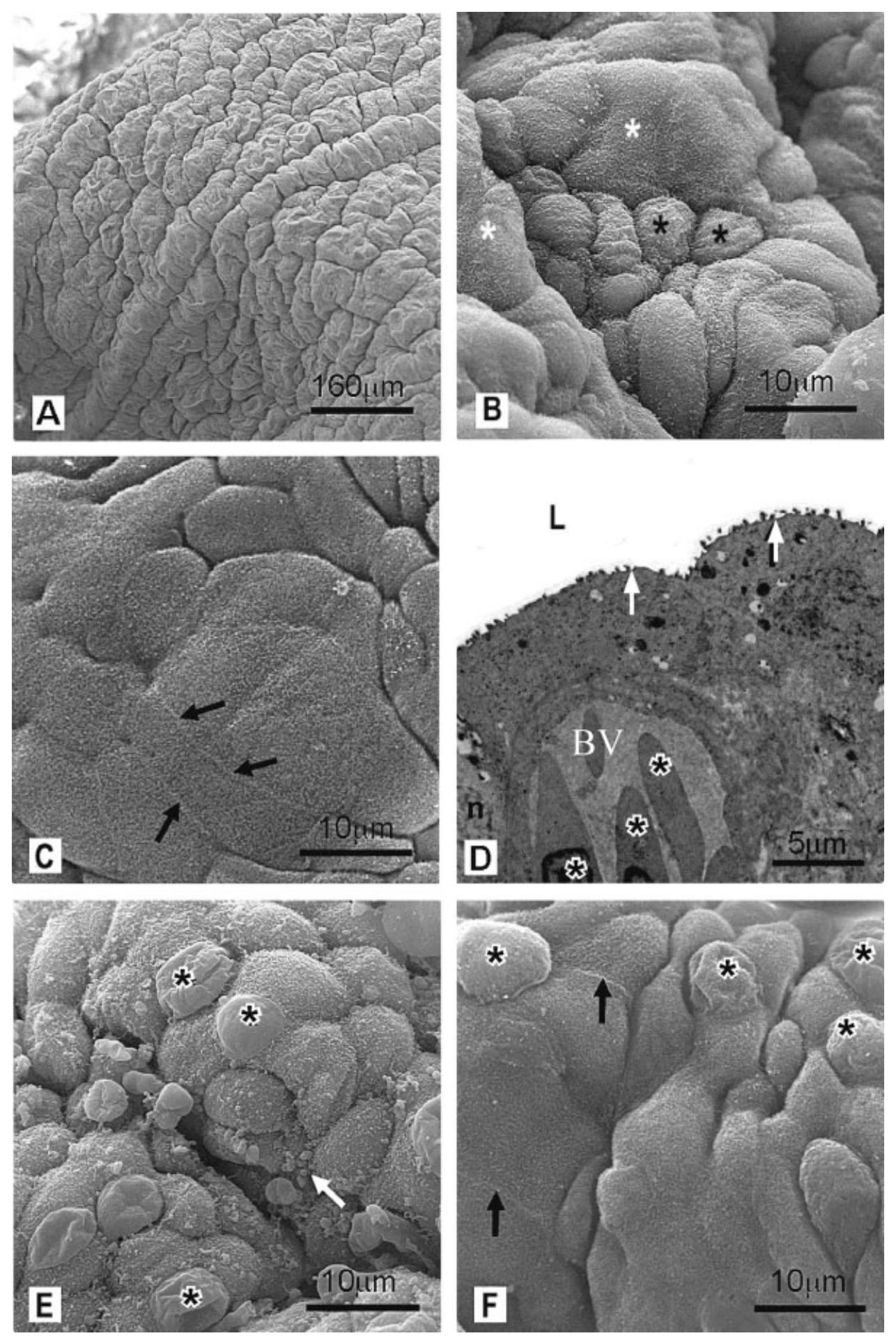

Fig. 5. Chorioallantoic placental differentiation; embryonic Stages 34-37 of Eulamprus tympanum. A: Stages 34-35 showing extensive parallel folding of the uterine epithelial surface; SEM. B: Stages 34-35. The blood vessels underlying the epithelial cells cause a variability in cell size and shape. Smaller protruding cells (black asterix); stretched larger cells (white asterix); SEM. C: Stages 34-35. Clusters of epithelial cells become stretched in the apical region from the thrust of the developing blood vessels below causing stretching of the apical membrane and exposure of the cell borders (arrows); SEM. D: Stages 34-35. Two microvillous cells with flattened apices and short microvilli (white arrows) and underlying blood vessel (BV). Red blood cells (asterix). The cell nucleus (n) sits laterally. L, uterine lumen; TEM. E: Stage 36. The smaller microvillous cells protrude maximally with bare apical plasma membrane (asterix). Small secretory vesicles (white arrow); SEM. F: Stage 37. Comparison of large attenuated cells with low microvillous covering and obvious cell borders (arrows) with developing smaller apically protruding cells with sparse, blebbed microvilli (asterix). 

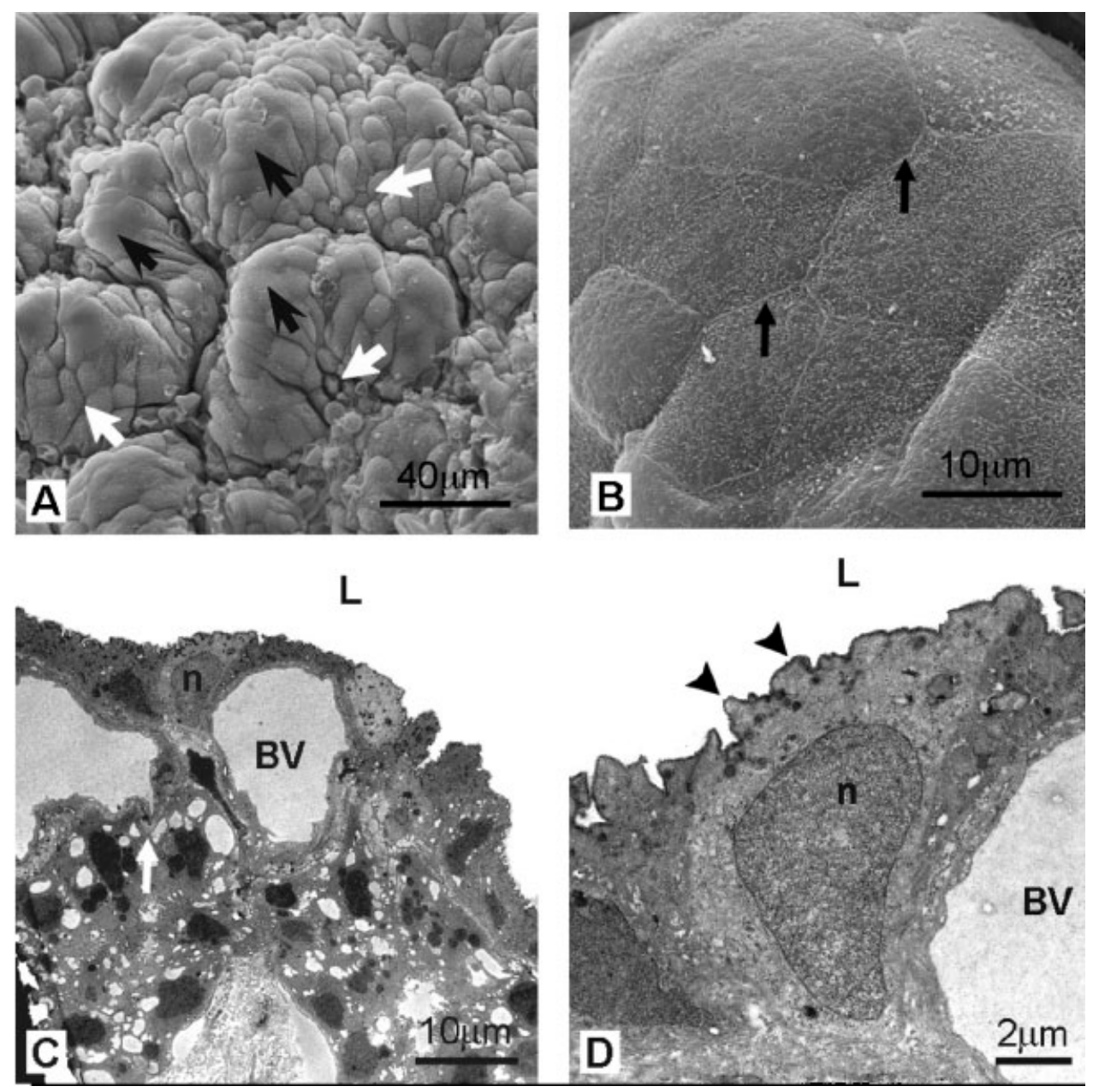

Fig. 6. Chorioallantoic placental differentiation; embryonic Stage 39 of Eulamprus tympanum. A: The uterine epithelium shows random, convex pouching into the lumen caused by expanding underlying blood vessels creating an alternating pattern of large stretched cells on the ridges (black arrows) and smaller cells in the gullies (white arrows); SEM. B: High magnification of the same cells shows clearly defined cell borders (arrows) and flattened surfaces of attenuated cells; SEM. C: Large blood vessels (BV) just below the epithelial surface; TEM. D: High magnification of (C) shows the apical surface of the epithelial cell is uneven and irregular due to the plicate arrangement of the microvilli (arrowheads); BV, blood vessel; $n$, displaced nucleus; L, uterine lumen. TEM.

\section{Embryonic Stage 40}

The uterine epithelium undergoes immense transformation at the end of gestation. At Stage 40 , just prior to birth, the uterus is not only distended and tense but also translucent and extremely thin walled. The chorioallantoic placenta and yolk sac placenta are no longer distinguishable in this last stage of gestation. The epithelium is very flat and smooth (Fig. 10A), and cellular definition is lost. Ciliated cells are still not apparent and the microvillous cells are large, extremely flat and covered with further reduced thin, plicate, and low microvilli so that the apical cell membrane is obvious (Fig. 10B).

\section{Postparturition at $48 \mathrm{~h}$}

The uterine epithelium has lost the stretched, flat appearance of Stage 40, and is uniformly folded $48 \mathrm{~h}$ postpartum (Fig. 11A). The microvillous cells have lost the flatness of Stage 40 and are now uniform in shape with slight apical protrusion and dense plicate microvilli (Fig. 11B). Ciliated cells and secretory vesicles are absent. Electron-dense vesicles are located in a thick band at the apical surface of the epithelial cells (Fig. 11C).

\section{Postparturition at 2 Weeks}

The uterine epithelium has undergone a vast, transformation by 2 weeks after birth. The epithelium is arranged into small, raised mounds of both ciliated and microvillous cells (Fig. 12A,B). Ciliogenesis is evident by the variability of cilia length and number (Fig. 12B), but there are also mature ciliated cells present. There is also variability of microvillar shape and height and an increase in density. The microvillous cells are again columnar 

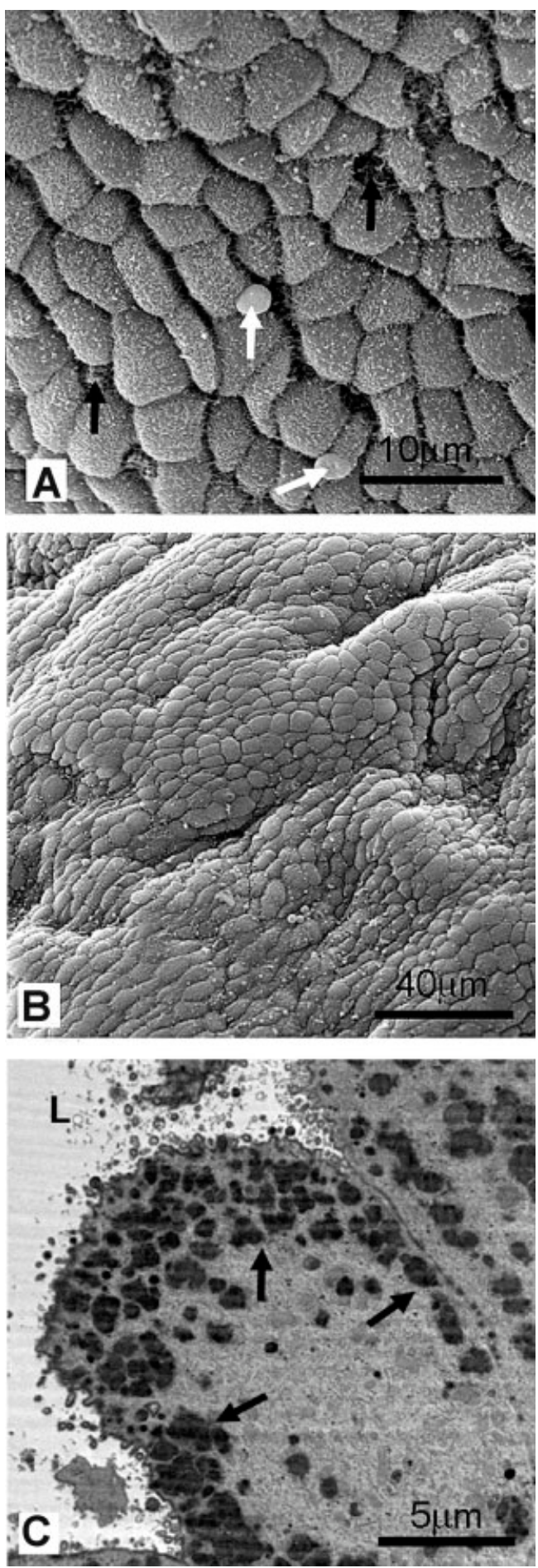

Fig. 7. Yolk sac placental differentiation; embryonic Stages 29-32 of Eulamprus tympanum. A: Stage 29. Ciliated cells are sunken and the cilia numerically reduced (black arrows). The microvillous cells show moderate apical protrusion and are covered with short, blebbed microvilli; SEM. B: Stages 31-32. Comparison of topography to the chorioallantoic placenta (Fig. 4) shows an absence of ridges, distinct folding pattern or groups of stretched cells. The microvillous cells are uniform in size and shape; SEM. C: Stages 31-32. The apical cytoplasm has a band of electrondense vesicles (arrows). White arrows, secretory vesicles; TEM. with mild to moderate apical protrusion and small electron-dense vesicles are localized in the apical cytoplasm (Fig. 12C).

\section{Plasma Progesterone Concentrations}

Plasma progesterone concentrations were low $(\leq 1.1 \mathrm{ng} / \mathrm{ml})$ in nonreproductive, postpartum, and early vitellogenic females (Fig. 13). Concentrations began to rise during late vitellogenesis with two of three samples recorded as $>11 \mathrm{ng} / \mathrm{ml}$. Concentrations then rose significantly as gestation progressed, reaching peak values at embryo Stages 28-30, and declining from Stage 35 through later gestation (Stages 36-39). In the single animal with embryos staged at 40 , progesterone concentrations had fallen to $0.9 \mathrm{ng} / \mathrm{ml}$.

\section{DISCUSSION}

The uterine epithelium of each stage of gestation changes characteristically as gestation progresses. The microvillous cells of the uterine epithelium of Eulamprus tympanum are columnar and exceptionally tall with the apical cytoplasm bulging into the lumen in nonreproductive females (Hosie et al., 2003; Adams et al., 2005). As with the oviparous lizards Crotaphytus collaris and Eumeces obsoletus (Guillette et al., 1989) and the viviparous snake, Thamnophis elegans (Mead et al., 1981; Motz and Callard, 1991), the hypertrophy quickly disappears once gestation begins. Similar apical hypertrophy also occurs in the oviparous turtle, Chrysemys picta (Mead et al., 1981), and suggests a commonality in uterine cells, regardless of mode of parity. The cellular hypertrophy in reproductively quiescent lizards indicates hormonal stimulation in readiness for vitellogenesis (Girling, 2002).

Dramatic changes occur in the number and form of ciliated cells during the reproductive cycle. The number of ciliated cells increases greatly during vitellogenesis, but then falls again as gestation progresses to be almost absent at the time of placental differentiation (Stage 30 onwards). The sudden increase in well-developed ciliated cells prior to ovulation suggests that they may be controlled by hormonal changes (Murphy et al., 2000), possibly reflected in the rising levels of plasma progesterone at this stage; unfortunately, low plasma volumes did not permit assay of estradiol in our samples. These cells may have a role in the transport of the embryo down the uterus via the wavelike motile function of their cilia as well as participating in sperm transport for fertilization.

A sudden rise in plasma progesterone prior to ovulation stimulates the uterine epithelium in oviparous species, resulting in cellular hypertrophy (Jones and Baxter, 1991; Girling et al., 1998) that is associated with storage of protein and cal- 

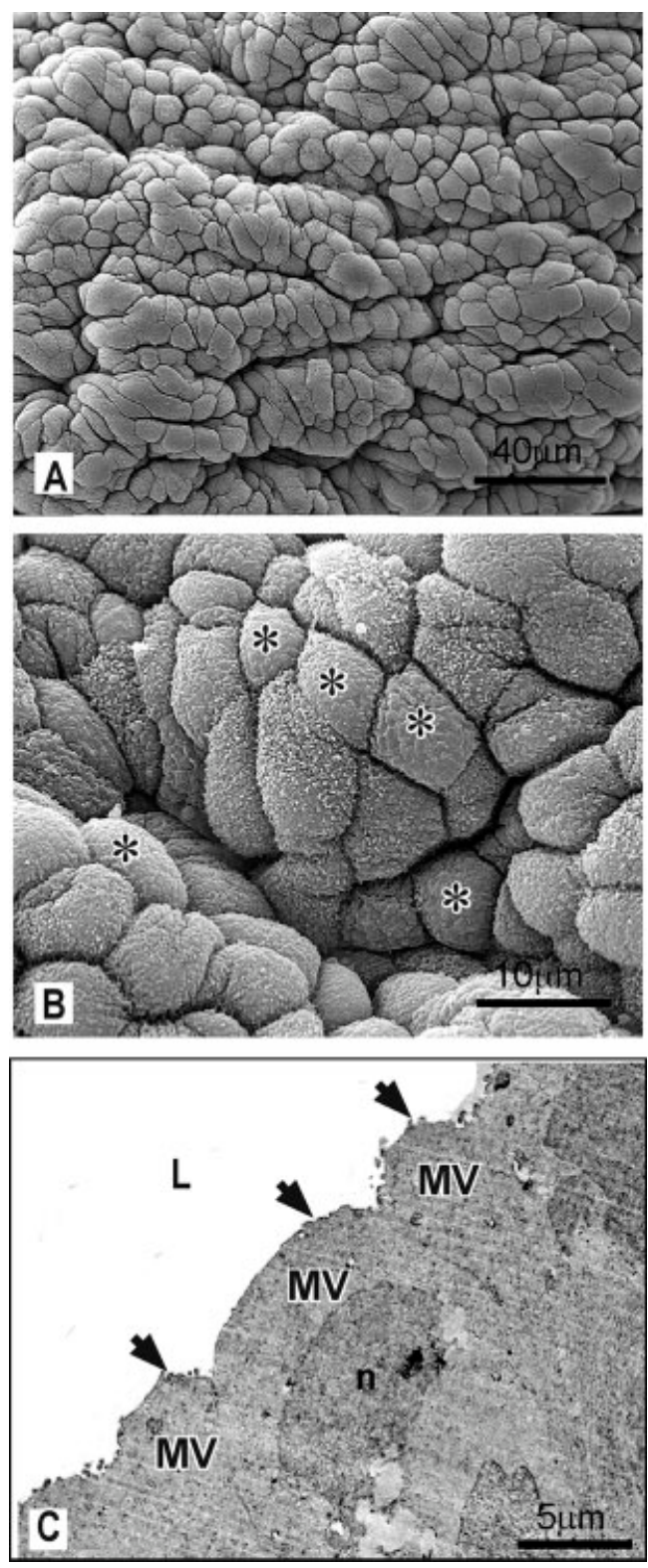

Fig. 8. Yolk sac placental differentiation; embryonic Stages 34-35 of Eulamprus tympanum. A: The uterine epithelium is no longer flat but has a puckered effect; SEM. B: The apical cellular surface has a knobbled appearance (asterix) and microvilli are greatly reduced; SEM. C: Flattened apices of the microvillous cells (MV). Electron-dense vesicles and secretory droplets are absent. $\mathrm{n}$, nucleus; L, uterine lumen; arrowheads, blebbed microvilli; TEM.

careous material of the eggshell (Guillette et al., 1989; Palmer et al., 1993); the epithelial cells are highly secretory during the egg shelling period, losing all microvillous structure on the apical surface (Guillette et al., 1989; Girling et al. 1998). The eggshell becomes a major source of calcium for embryos in oviparous species, once the shelled eggs are oviposited (Packard et al., 1985). The rise in plasma progesterone in Eulamprus tympa- num may reflect similar changes to their uterine cells, which may represent a source of calcium from maternal tissue. In viviparous species, however, there is no calcareous eggshell, and so the uterus provides calcium for embryos that are retained for all of embryonic development (Stewart and Thompson, 2000). A significant provision of calcium is from the maternal placenta and hypertrophy in the uterine epithelial cells may be responsible for calcium production and transport in viviparous squamates.

The rise in plasma progesterone is extended in Eulamprus tympanum compared to oviparous species (Jones and Swain, 1996), and reflects the pattern in macropodid marsupials (Freyer et al., 2003), where the extended elevation of progesterone is linked to an extended secretory phase and maintenance of gestation. Hence, extended elevation of plasma progesterone concentrations in $E$. tympanum is probably also associated with uterine secretion and the maintenance of gestation that is likely to be other than calcium production. The similarity in preovulatory morphology during the vitellogenic and reproductively quiescent phase between oviparous species and viviparous species with simple placentae (Thompson et al., 2006; Adams et al., 2007) supports the premise that very few changes are required for the evolution from oviparity to viviparity (Shine and Bull, 1979; Blackburn, 1993).

Cilia are reduced in length and density and the cell size is smaller than that of the surrounding microvillous cells by the time the chorioallantoic placentae and yolk sac placentae differentiate (about Stage 30). The uterine epithelium of the chorioallantoic placenta develops distinct folding patterns, indicating an increase in cellular activity in the uterus with the changes in reproductive conditions. The microvillous cells eventually rearrange to develop a dense cover of microvilli and form the two types of placentae.

The decline and absence of ciliated cells during gestation suggest that the ciliated cells are reacting to the mechanisms regulating the formation of the two placentae and possibly to factors released by the developing embryo. The increase of ciliated cells prior to ovulation, presence during early stages of gestation and decrease during gestation, is found in squamates with both complex and simple placentae, Hoplodactylus maculatus (Girling et al., 1997), Chalcides ocellatus tiligugu (Corso et al., 2000), and Pseudemoia entrecasteauxii (Adams et al., 2005). Presence of cilia at the time of ovulation is probably associated with the movement of ovum down the reproductive tract.

Previous studies describe the regression of ciliated cells by the loss in the abundance of cilia and reduction in cell number (Girling et al., 1997). In the early stages of gestation of Eulamprus tympa- 

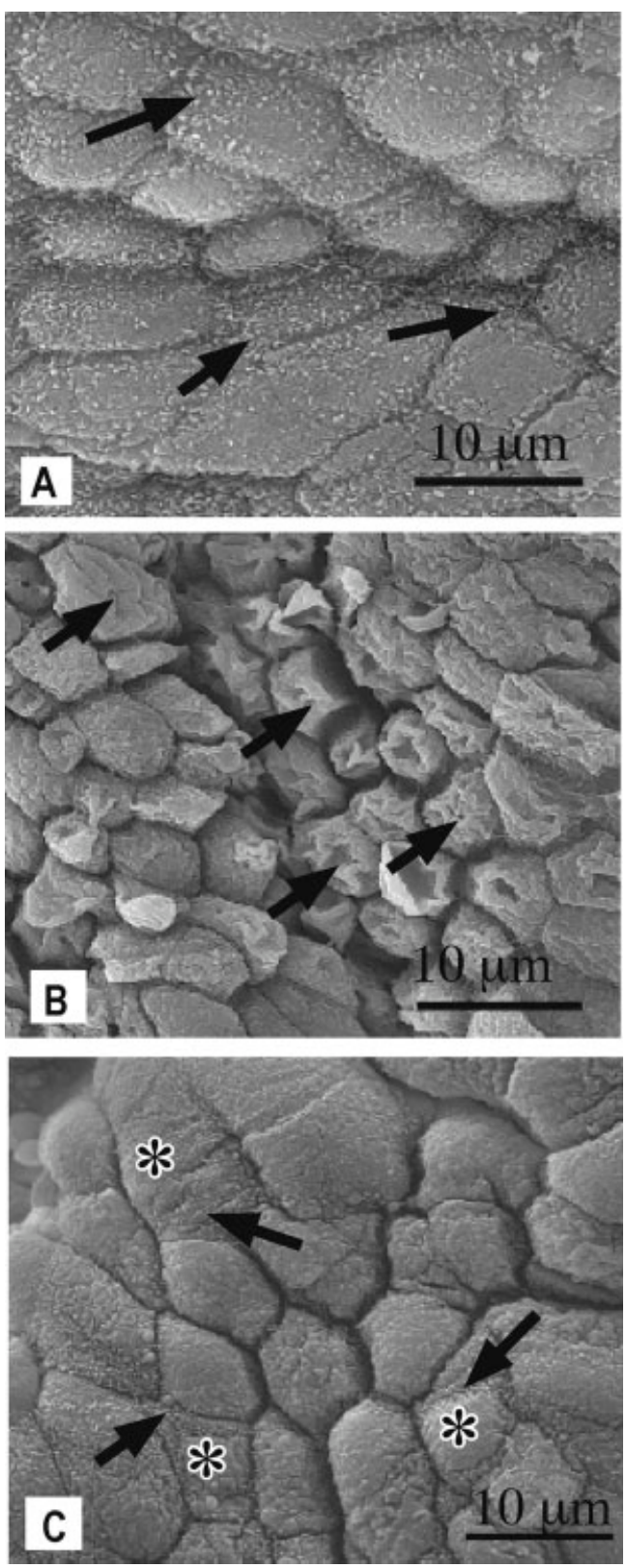

Fig. 9. Yolk sac placental differentiation; embryonic Stages 37-39 of Eulamprus tympanum. A: Stage 37. The microvillous cell size and shape show large variability with minimal apical protrusion; short microvilli appear at peripheral apices and borders (arrows); SEM. B: Stage 38. Wrinkled apical plasma membranes show cells in various stages of collapse (arrows); SEM. C: Stage 39. The central apices are knobbled (asterix) with dense, short microvilli laterally (arrows); SEM.

num, the ciliated cells appear to be overhung and covered by the swollen apices of adjacent microvillous cells, but as gestation progresses through mid- to late gestation the ciliated cells disappear altogether. The overgrowth is especially evident by the hypertrophic microvillous cells during quiescence and vitellogenesis.

\section{Ontogeny and Function of the Chorioallantoic Placenta}

Features that distinguish the uterine components of the chorioallantoic placentae and yolk sac placentae begin to be apparent at embryonic Stage 29 and, by Stages 31-32, the two placental regions are clearly defined. As gestation proceeds, the characteristics of the two placentae diverge further, presumably reflecting different functions. The smooth-surfaced hypertrophic microvillous cells of the nonreproductive and vitellogenic uterine epithelia reduce in height and develop apical microvilli in the chorioallantoic placenta during the early stage of gestation, as also occurs in the viviparous gecko Hoplodactylus maculatus (Girling et al., 1997) and is similar to the morphology after ovulation in oviparous species (Mead et al., 1981; Palmer et al., 1993; Adams et al., 2004). As gestation progresses, cell borders become visible as the microvillous cells become increasingly stretched and attenuated from the expansion and impingement of underlying blood vessels. These vessels therefore cause epithelial ridges to form at the luminal surface, allowing easy luminal exposure of the flattened, attenuated cells for close apposition with the embryonic membranes. This surface morphology is consistent with the flat apposition of maternal and fetal tissues described in the Type I placental classification of Weekes (1935). The flattened aggregations of cells with thinned apical cytoplasm allow the chorioallantoic placenta of Eulamprus tympanum to be well adapted for gas exchange as the resistance to gas diffusion is progressively reduced during gestation by (1) the development of vascularity towards the lumen; (2) displacement of nuclei and other cytoplasmic components, reducing the cellular barriers and minimizing the resistance to gas diffusion; (3) the thinning and attenuation of the apical cytoplasm by the development of capillaries close to the luminal surface; and (4) the presence of microvilli, which increases the surface area available for diffusion.

The characteristic features of the chorioallantoic placenta of Eulamprus tympanum are fully expressed during mid-late gestation (Stages 31-39). They are consistent with the oxygen needs of the embryo, which are the highest during late development (Thompson, 1989; Andrews, 2004). The timing of the characteristic morphology is also consistent with the finding that a large portion of maternal inspiration of oxygen in E. tympanum, during the later stages of gestation, contributes directly to the development of the embryo (Robert and Thompson, 2000). The chorioallantoic placental vascular development of the uterine epithelium in $E$. tympanum is consistent with the simple chorioallantoic placental development of the viviparous snakes Thamnophis ordinoides (Blackburn et al., 2002), T. sirtalis and T. radix (Blackburn and 


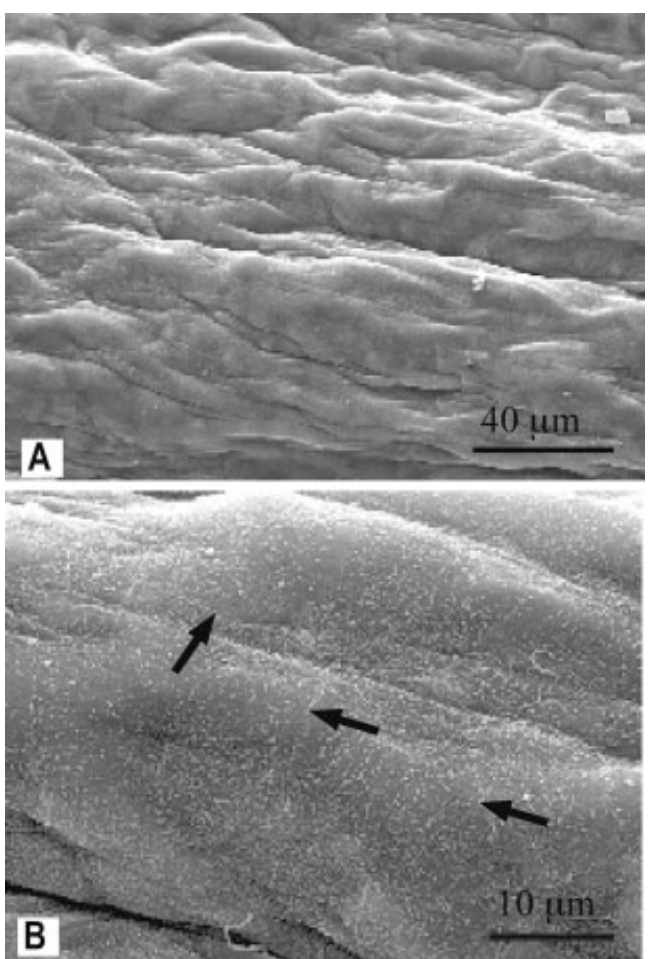

Fig. 10. Embryonic Stage 40 of Eulamprus tympanum. The chorioallantoic placenta and the yolk sac placenta are no longer distinguishable. A: The epithelial topography is very flat and smooth and the cellular definition is lost; SEM. B: Ciliated cells are not apparent and the microvillous cells are large, extremely flat and covered with thin, plicate and low microvilli so that apical cell membrane is exposed. Cell borders are obvious (arrows); SEM.

Lorenz, 2003) and viviparous lizards, $H$. maculatus (Girling et al., 1997), and Elgaria coerulae (Stewart and Castillo, 1984).

Species with complex placentae also have a similar pattern of attenuation and vascular development for gas exchange to Eulamprus tympanum, but the cellular attenuation develops to a greater degree (Adams et al., 2005). The overlying epithelial cytoplasm of the paraplacentome in lizards with more complex placentae than $E$. tympanum, e.g., Pseudemoia entrecasteauxii, decreases to just $0.5 \mu \mathrm{m}$ (Adams et al., 2005). The epithelial cytoplasm between the blood vessels and lumen in E. tympanum is thin at Stage 39 , but the thickness is about an order of magnitude greater than $P$. entrecasteauxii $(\sim 5 \mu \mathrm{m}$ compared to $0.5 \mu \mathrm{m})$. The difference in epithelial distance suggests a difference in the efficiency of oxygen transfer between complex and simple placentae where $P$. entrecasteauxii appears adapted for more efficient oxygen exchange.

The classification of Weekes (1935), which was based on light microscopy, defined Type I chorioallantoic placentae as having a flat apposition of squamous epithelia on both the maternal and fetal sides. Our high resolution electron microscopy reveals that the maternal uterine epithelium of Eulamprus tympanum (called Hinulia quoyi by Weekes, 1927) is not a simple squamous layer, but consists of columnar cells that are extremely attenuated on the ridge apices because of the underlying pressure of the increasing vasculature. Thus, the simple chorioallantoic placenta of E. tympanum is more complex than originally thought.

Uterodomes are smooth, apically bare luminal protrusions of the cellular surface found in many mammals (Murphy, 2004). They are distinct from other smooth luminal protrusions, such as secretory vesicles and pinopods, in that uterodomes occupy the entire cell surface (Murphy et al., 2000; Adams et al., 2002). At Stage 36, the smooth dome structures in the chorioallantoic placenta have the surface characteristics of uterodomes. This is consistent with the presence of uterodomes previously found in Eulamprus tympanum in the embryonic (chorioallantoic placenta) hemisphere (Hosie et al., 2003). The presence of uterodomes has been tightly linked to the increase in progesterone concentration, which, in mammals, is often associated with early gestation and more notably, implantation (Enders and Nelson, 1973). In E. tympanum, the peak of plasma progesterone occurs during mid-gestation between Stages 31 and 33. The peak coincides with the presence of uterodomes during gestation (Hosie et al., 2003) just after the progesterone peak and may suggest that in the simple placenta, uterodomes, stimulated by progesterone, are associated with placental development and the establishment of the connection between maternal and fetal epithelia.

\section{Ontogeny and Function of the Yolk Sac Placenta}

During development, the differentiation of the yolk sac placenta forms in two stages. Initially, the yolk sac placenta is formed followed by the formation of the omphalallantoic placenta (Weekes, 1927; Villagran et al., 2005). Differentiation of the uterine side of the yolk-sac placenta in Eulamprus tympanum occurs at the same time as the chorioallantoic placenta and persists throughout gestation. The cellular changes in the yolk sac placenta during gestation in E. tympanum are more subtle than in the chorioallantoic placenta. At the time of differentiation (embryonic Stage 29), the uterine epithelial cells of the yolk sac placenta are single and clearly demarcated. From Stages 30-36, the cellular surface has a "knobbled" appearance and is different from the smooth appearance found during the nonreproductive phase. We suggest that the rough, knobbled appearance of the apical plasma membrane in both placentae is closely associated with the minute secretory droplets either just secreted, or about to be secreted, into the 

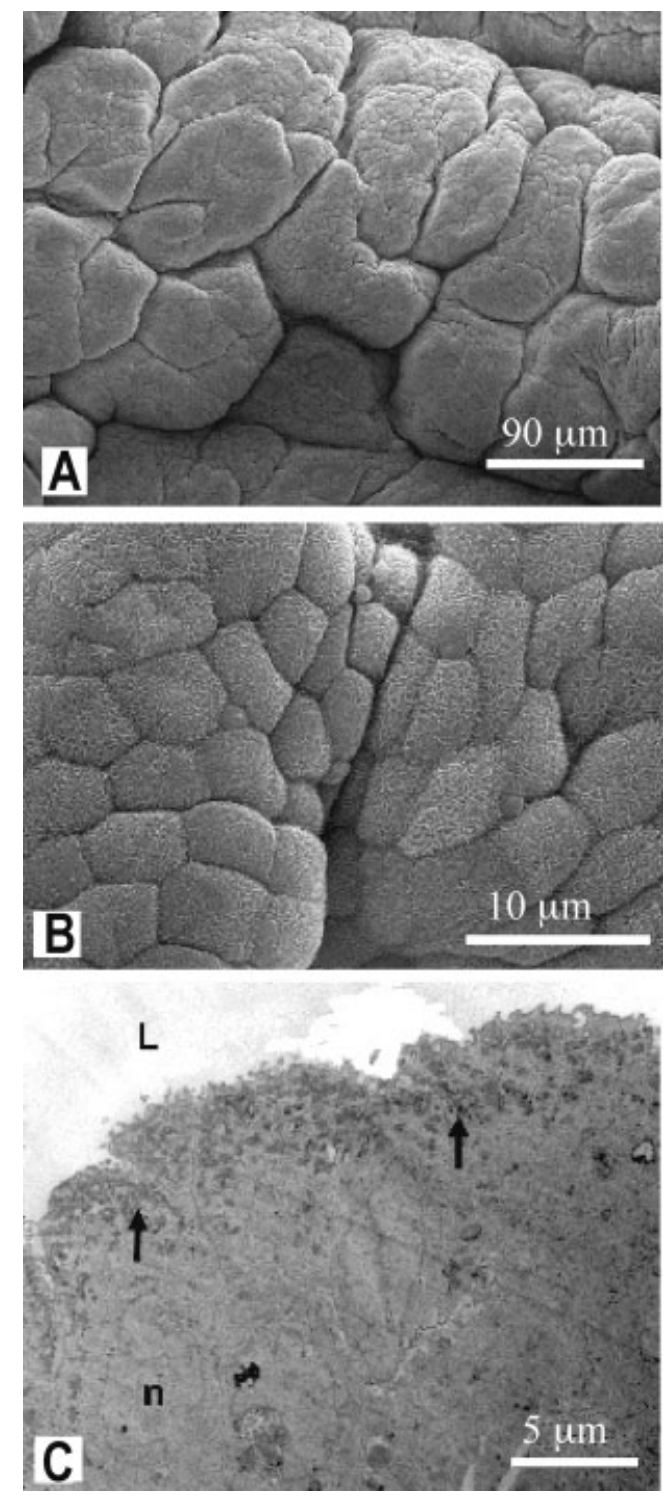

Fig. 11. Post parturition at $48 \mathrm{~h}$ in Eulamprus tympanum. A: The uterine epithelium is uniformly folded; SEM. B: The microvillous cells have lost the flatness of Stage 40 and are uniform in shape with slight apical protrusion. They are covered with dense, plicate microvilli; SEM. C: Ciliated cells and secretory vesicles are absent. Electron-dense vesicles are located in a band at the apical cell surface (arrows). L, uterine lumen; n, nucleus; TEM.

uterine lumen, thus causing either a disruption or protrusion of the membrane, resulting in an uneven surface. Electron-dense vesicles in the epithelial cells of nonreproductive uteri increase in number and occur in abundance in the omphloplacenta at Stages 31-32. By embryonic Stage 37, the single cells have formed cellular aggregations with microvilli placed peripherally. Unlike the aggregating cells in the chorioallantoic placenta, the yolk sac placenta does not arrange into an organized pattern of alternating aggregated and singular cells but has a random undulating appearance, suggesting that the aggregations are not formed by blood vessels immediately beneath the epithelium but may be due to physical attenuation caused by the growth of the embryo.

The functions of the yolk sac placenta in Eulamprus tympanum are unclear, but electron-dense secretory vesicles in the omphloplacenta have been implicated in histotrophic transfer in the lizards Pseudemoia entrecasteauxii (Adams et al., 2005), Chalcides ocellatus tiligugu (Corso et al., 2000), and the snake Virginia striulata (Stewart and Brasch, 2003), species that have complex yolk sac placentae. E. tympanum is mostly lecithotrophic (Thompson et al., 2000), but the TEM implicates it in transport of matter to the uterine lumen. Presumably, some of that is taken up by the embryo, even though there is little net uptake of dry matter during development (Thompson et al., 2000). The data on net uptake, however, says nothing about flux and it is likely that the yolk sac placenta of $E$. tympanum is responsible for the provision of some nutrient to the embryo, although the nature of that material is not known. The presence of microvilli and irregular-shaped glands in the lamina propria suggests a secretory function in late gestation.

\section{Embryonic Stage 40}

Radical changes in morphology occur at Stage 40 where all of the cellular characteristics of gestation are lost and, in the single animal studied, plasma progesterone concentrations are basal. The microvillous morphology has changed and the epithelial cells are extremely flat. The rapid metamorphosis from Stage 39 (where the two placentae are still evident) to Stage 40 suggests that the physical capability of the uterus to accommodate the size of the embryo may have reached its limit. Other factors observed at dissection are consistent with this suggestion. The embryos burst out of their transparent incubation chambers during excision and are fully mobile indicating a late Stage 40 . The yolk reserves are also depleted, further suggesting the maximum growth of the embryo had been reached in utero. This loss of the placental features and flattening of the epithelial cells suggests that the two placentae are of no further use in the period just prior to birth. Despite the exhausted yolk supply, there is no further nutrient supply via the placenta during prolonged periods of embryonic Stage 40 in Niveoscincus metallicus (Swain and Jones, 2000), and the same is probably true for Eulamprus tympanum. The extreme thinness of the maternal wall at Stage 40 may be sufficient for vascular diffusion of oxygen and prevention of hypoxia in $E$. tympanum. 

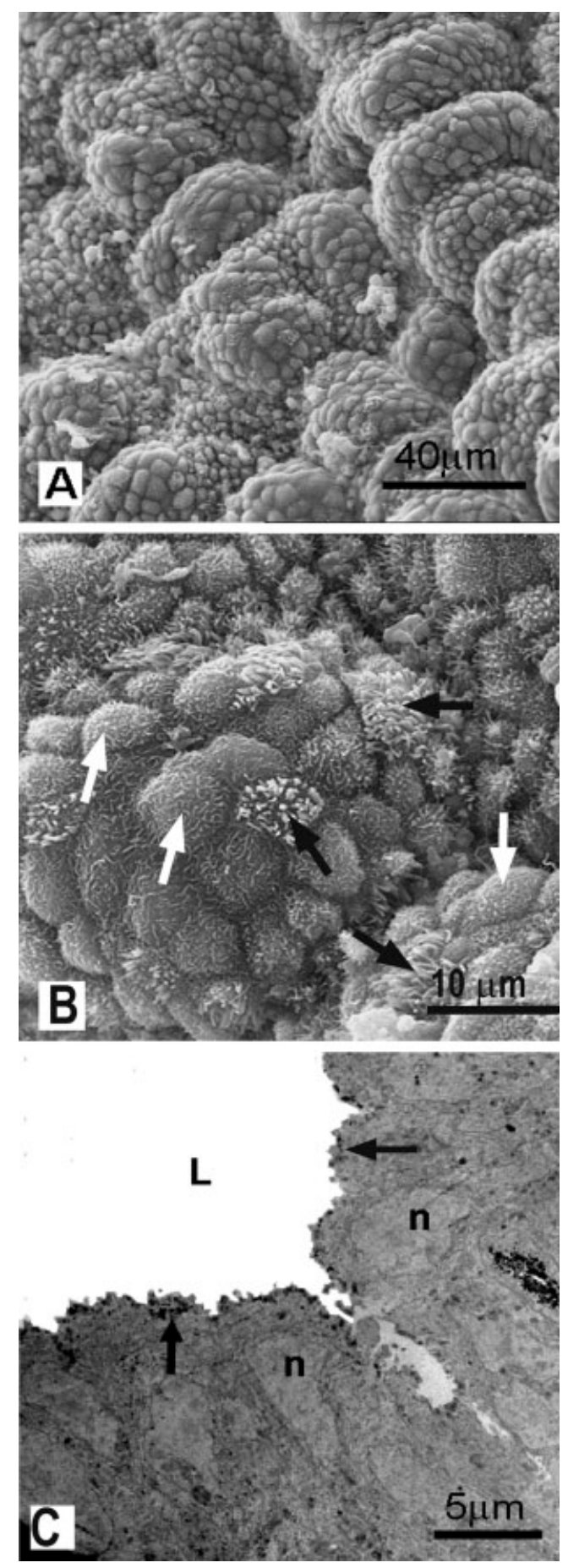

Fig. 12. Post parturition at 2 weeks in Eulamprus tympanum. A: The epithelium is arranged into small, raised mounds of both ciliated and microvillous cells; SEM. B: Ciliogenesis is evident (black arrows); microvillous arrangement is variable (white arrows); SEM. C: The microvillous cells are again columnar with moderate apical protrusion; small electron-dense vesicles are localized at the apical periphery (arrow). L, uterine lumen; n, nucleus; TEM.

\section{Postparturition}

The columnar microvillous epithelial cells have regained cellular shape and are covered densely with plicate microvilli by $48 \mathrm{~h}$ postpartum, suggesting a secretory role during this stage of recovery. By 2-week postparturition, ciliated cells reappear in abundance and in various stages of ciliogenesis. The reappearance of the ciliated cells suggests a role in maintaining the luminal surface by moving mucous secretions and cellular debris associated with labor through the uteri (Palmer and Guillette, 1988). There are no reproductive studies that describe postbirth uterine morphology in squamates and especially the transition from gestation to postparturition. In this study, the period of recovery after birth shows that massive cellular activity with cells at different stages of microvillar and cilia development is evident 2 weeks after birth and the reproductively quiescent conditions take longer to achieve.

\section{Timing of Placental Differentiation}

During reproductive quiescence, the uterine epithelium has a relatively flat surface, forming folds and ridges as the epithelium approaches gestation. It eventually differentiates into the chorioallantoic placenta and yolk sac placenta by mid-gestation at about Stage 29. Despite the presence of an embryo in the oviduct, the two placentae are relatively underdeveloped and difficult to distinguish before Stage 29. Earlier embryos appear as round spheres of yolk and cells, and even at Stage 29, there are few features that clearly differentiate the two placentae. The period where placental differentiation is distinct in the uterine epithelium (between Stages 29 and 32) coincides approximately with the timing of oviposition in oviparous species (Andrews and Mathies, 2000; Andrews, 2004).

In oviparous species, the egg shell acts as a barrier during prolonged gestation, restricting the availability of oxygen (Andrews and Mathies, 2000; Warner and Andrews, 2003), and hypoxia can have a detrimental affect on embryonic differentiation, growth, mortality, and body size at hatching (Andrews and Mathies, 2000). Oviposition occurs at a stage when embryonic oxygen demands begin to increase and exposure of the egg shell to oxygen in the atmosphere facilitates normal, embryonic growth (Andrews, 2004). Placental differentiation in the simple viviparous Eulamprus tympanum suggests that the timing of placental differentiation is primarily due to the increase in functional requirements for normal embryonic growth, rather than the simple presence of an embryo. The coincidence between the time of oviposition and placental differentiation demonstrates a similarity during gestation in the uterus between oviparous and simple placental viviparous squamates.

In summary, there are definite morphological characteristics that differentiate the chorioallantoic and yolk sac placentae in Eulamprus tympa- 


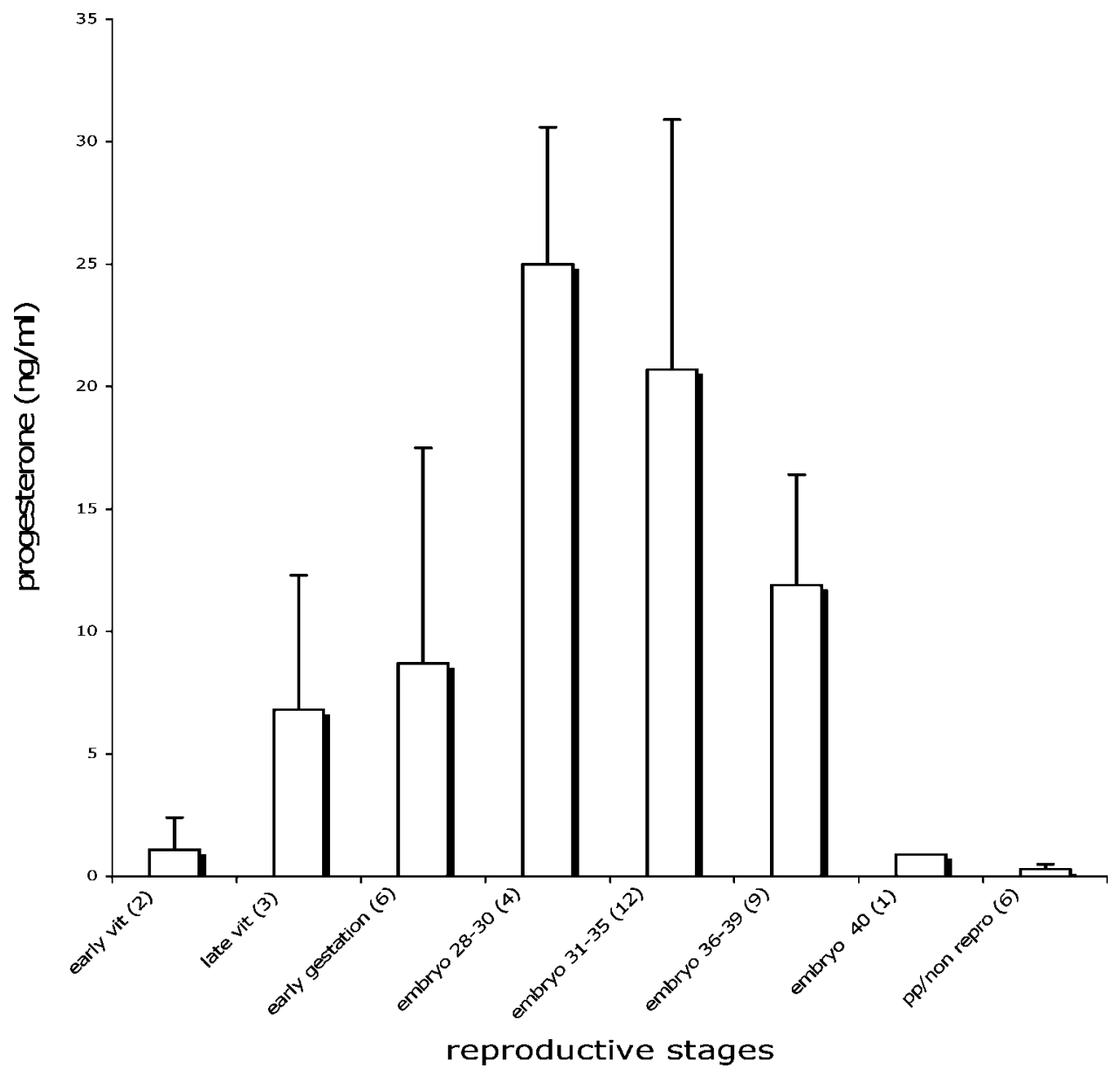

Fig. 13. Plasma progesterone conce ntration (mean \pm SD) in Eulamprus tympanum through the reproductive cycle (sample size).

num. The differentiation does not begin until embryonic development has proceeded to the normal time of oviposition in oviparous species. We propose that the differences in placental differentiation reflect different functions for each placenta, with the chorioallantoic placenta being the site for gas exchange and the yolk sac placenta being the site of secretion of matter into the uterine lumen, where it is presumably taken up by the embryo. These proposals require functional studies to test them.

\section{ACKNOWLEDGMENTS}

Electron microscopy was conducted at the Key Centre for Microscopy, the Electron Microscope Unit at the University of Sydney. Animals were collected with NSW National Parks and Wildlife Service Scientific Permit A2438 and research was conducted with University of Sydney Animal Ethics number L04/1-2003/3/3682. J. Herbert collected and prepared tissue for processing of the lizards.

\section{LITERATURE CITED}

Adams SM, Gayer N, Hosie MJ, Murphy CR. 2002. Human uterodomes (pinopods) are not pinocytotic. Hum Reprod 17:19801986.

Adams SM, Hosie MJ, Thompson MB, Murphy CR. 2004. Changes in oviductal morphology of the skink. Lampropholis guichenoti, associated with egg production. J Morphol 262:536-544.

Adams SM, Biazik JM, Thompson MB, Murphy CR. 2005. The cyto-epitheliochorial placenta of the viviparous lizard Pseudemoia entrecasteauxii: A new placental subtype. J Morphol 264:264-276.

Adams SM, Biazik J, Stewart RL, Murphy CR, Thompson, MB. 2007. Fundamentals of viviparity: Comparison of seasonal changes in the uterine epithelium of oviparous and viviparous Lerista bougainvillii (Squamata: Scincidae). J Morphol (in press).

Andrews RM. 2004. Reptilian incubation: Environment, evolution, and behaviour. In: Deeming DC, editor. Embryonic Development. UK: Nottingham University Press. pp 75-102.

Andrews RM, Mathies T. 2000. Natural history of reptilian development: Physiological constraints on the evolution of viviparity. Bioscience 50:227-238.

Blackburn DG. 1993. Chorioallantoic placentation in squamate reptiles: structure, function, development, and evolution. J Exp Zool 266:414-430. 
Blackburn DG, Lorenz RL. 2003. Placentation in garter snakes. II. Transmission EM of the chorioallantoic placenta of Thamnophis radix and $T$. sirtalis. J Morphol 256:171-186.

Blackburn DG, Stewart JR, Baxter DC, Hoffman LH. 2002. Placentation in garter snakes: Scanning EM of the placental membranes of Thamnophis ordinoides and T. sirtalis. J Morphol 252:263-275.

Corso G, Giuseppe MD, Carcupino M. 2000. Uterine morphology during the reproductive cycle in Chalcides ocellatus tiligugu (Gmelin) (Squamata: Scincidae). J Morphol 243:153165.

Dufaure JP, Hubert J. 1961. Table de development de lezard vivipare: Lacerta (Zootoca) vivipara Jacquin. Arch Anat Micros Morphol Exp 50:309-328.

Durden LA, Dotson EM, Vogel GN. 1995. Two efficient techniques for catching skinks. Herpetol Rev 26:137.

Enders AC, Nelson DM. 1973. Pinocytotic activity of the uterus of the rat. Am J Anat 138:277-300.

Freyer C, Zeller U, Renfree MB. 2003. The marsupial placenta: A phylogenetic analysis. J Exp Zool Part A: Com Exp Bio 299:59-77.

Girling JE. 2002. The reptilian oviduct: A review of structure and function and directions for future research. J Exp Zool 293:141-170.

Girling JE, Cree A, Guillette LJ Jr. 1997. Oviductal structure in a viviparous New Zealand gecko, Hoplodactylus maculatus. J Morphol 234:51-68.

Girling JE, Cree A, Guillette LJ. 1998. Oviductal structure in four species of Gekkonid lizard differing in parity mode and eggshell structure. Reprod Fertil Devel 10:139-154.

Guillette LJ, Fox SL, Palmer BD. 1989. Oviductal morphology and egg shelling in the oviparous lizards Crotaphytus-collaris and Eumeces-obsoletus. J Morphol 201:145-160.

Hosie MJ, Adams SM, Thompson MB, Murphy CR. 2003. Viviparous lizard, Eulamprus tympanum, shows changes in the uterine surface epithelium during early gestation that are similar to the plasma membrane transformation of mammals. J Morphol 258:346-357.

Jones RE, Baxter DC. 1991. Gestation, with emphasis on corpus luteum biology, placentation, and parturition. In: Jones RE, editor. Vertebrate Endocrinology: Fundamentals and Biomedical Implications, Vol. 4. San Diego: Academic Press. pp 205302.

Jones SM, Swain R. 1996. Annual reproductive cycles of reproductive hormones in plasma of female Niveoscincus metallicus. J Herpetol 30:140-146.

Junqueira LC, Carneiro J. 2005. Basic Histology, 11th ed. McGraw-Hill. p 502.

Martel D, Malet C, Gautray JP, Psychoyos A. 1981. Surface changes of the luminal uterine epithelium during the human menstrual cycle: A scanning electron microscopic study. In: de Brux J, editor. The Endometrium: Hormonal Impacts. New York: Plenum. pp 15-29.

Mead RA, Eroschenko VP, Highfill DR. 1981. Effects of progesterone and estrogen on the histology of the oviduct of the garter snake Thamnophis-elegans. Gen Comp Endocrin 45:345354.

Motz VA, Callard IP. 1991. Seasonal variations in oviductal morphology of the painted turtle Chrysemys picta. J Morphol 207:59-72.
Murphy CR. 2004. Uterine receptivity and the plasma membrane transformation. Cell Res 14:259-267.

Murphy CR, Hosie MJ, Thompson MB. 2000. The plasma membrane transformation facilitates gestation in both reptiles and mammals. Comp Biochem Physiol A 127:433-439.

Packard GC, Tracy CR, Roth JJ. 1977. The physiological ecology of reptilian eggs and embryos, and the evolution of viviparity within the class Reptilia. Biol Rev 55:71-105.

Packard MJ, Packard GC, Miller JD, Jones ME, Gutzke WH. 1985. Calcium mobilization water balance and growth in embryos of the Agamid lizard Amphibolurus barbatus. J Exp Biol 235:349-358.

Palmer BD, Guillette LJ. 1988. Histology and functional morphology of the female reproductive tract of the tortoise Gopherus polyphemus. Am J Anat 183:200-211.

Palmer BD, Demarco VG, Guillette LJ. 1993. Oviductal morphology and eggshell formation in the lizard. Sceloporus woodi. J Morphol 217:205-217.

Psychoyos MD, Nikas G. 1994. Uterine pinopods as markers of uterine receptivity. Ass Repro Rev 4:26-32.

Robert KA, Thompson MB. 2000. Energy consumption by embryos of a viviparous lizard. Eulamprus tympanum, during development. Comp Biochem Physiol A 127:481-486.

Shine R, Bull JJ. 1979. The evolution of live-bearing in lizards and snakes. Am Nat 113:905-922.

Smith SA, Shine R. 1997. Intraspecific variation in reproductive mode within the scincid lizard Saiphos equalis. Aust J Zool 45:435-445.

Stewart JR, Brasch KR. 2003. Ultrastructure of the placentae of the natricine snake, Virginia striatula (Reptilia: Squamata). J Morphol 255:177-201.

Stewart JR, Castillo RE. 1984. Nutritional provision of the yolk of two species of viviparous reptiles. Physiol Zool 57:377-383.

Stewart JR, Thompson MB. 2000. Evolution of placentation among squamate reptiles: recent research and future directions. Comp Biochem Physiol A 127:411-431.

Swain R, Jones SM. 2000. Maternal effects associated with gestation conditions in a viviparous lizard, Niveoscincus metallicus. Herp Mon 14:432-440.

Thompson MB. 1989. Patterns of metabolic development in embryonic reptiles. Resp Physiol 76:243-256.

Thompson MB, Stewart JR, Speake BK. Comparison of nutrient transport across the placenta of lizards differing in placental complexity. Comp Biochem Physiol A 127:469-479, 2000.

Thompson MB, Adams SM, Biazik JB, Lui S, Murphy CR. 2006. Morphological and functional changes to the uterus of lizards with different placental complexities. Herpetol Mon 20:178-185.

Villagran M, Mendez FR, Stewart JR. 2005. Placentation in the Mexican lizard Sceloporus mucronatus (Squamata: Phrynosomatidae). J Morphol 264:286-297.

Warner DA, Andrews RM. 2003. Consequences of extended egg retention in the Eastern fence lizard (Sceloporus undulatus). J Herp 37:309-314.

Weekes HC. 1927. Placentation and other phenomena in the scincid lizard Lygosma (Hinulia) Quoyi. Proc Lin Soc NSW 52:499-554.

Weekes HC. 1935. A review of placentation among reptiles with particular regard to the function and evolution of the placenta. Proc Linn Soc NSW 1935:625-645. 